\title{
A REVIEW OF 180 CHILDREN SUFFERING FROM RHEUMATISM, CHOREA AND CARDITIS.
}

BY

\author{
ROBERT MARSHALL, M.D., F.R.C.P.I., D.P.H. \\ Physician, Ulster Hospital for Children \& Women ; \\ Assistant Physician, Royal Victoria Hospital, Belfast.
}

This paper represents the result of an attempt made at the Ulster Hospital for Children and Women to take stock of what knowledge has been gained of a series of 180 children attending the Hospital for one or more of the triad, rheumatism, chorea and carditis.

TABLE I.

Analysis of 180 Cases of Rheumatism or Chorea in Children.

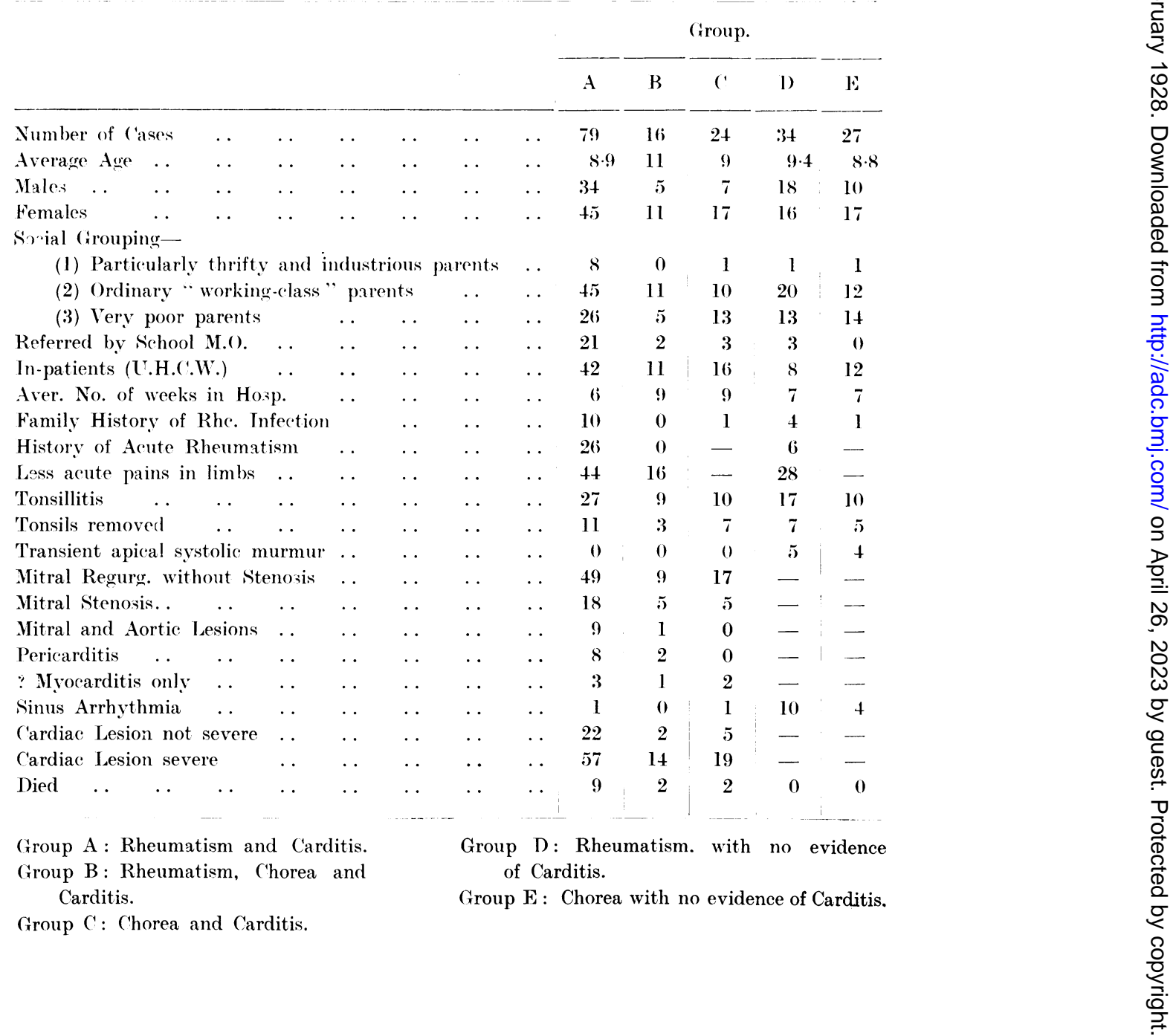


For this purpose I have arranged the series in five groups (vide Table I) :

Group A. 'Rheumatic' children with evidence of carditis.

Group B. Children who have had limb-pains, chorea, and carditis.

Group C. Children who have had chorea, and carditis, but no limb-pains.

Group D. Children who have had limb-pains, but show no evidence of carditis.

Group E. Children who have had chorea, but neither limb pains nor evidence of carditis.

\section{Group A. (Rheumatism and Carditis.)}

This is the "rheumatic" group; all these children have suffered more or less severely from rheumatic pains. The average age of first attendance at Hospital was almost 9 years; the majority were girls. I have attempted, with the aid of the Sister-in-charge of the Out-Patient Department, to divide them into three groups according to the economic position of their parents ; I am satisfied that all were suitable for hospital treatment, but some were better off than others. It will be seen that most were graded in the second group of ordinary working class parents, more or less regularly employed.

42 of these children were in-patients and the average duration of their stay in Hospital was six weeks.

In 26 cases there was a history of a rheumatic attack of such severity as to keep the child in bed : 44 had pains varying from slight so-called growing pains to something short of true acute rheumatism ; in the remaining 9 , while there was evidence of rheumatic toxæmia, such as lassitude, pallor and loss of weight, pain was slight or absent. I have kept no record of the frequency of rheumatic nodules. 27 had tonsillitis recorded in the notes, and in 11 of these tonsillectomy was performed; in some cases the parents declined consent, and in some the severity of the cardiac condition was a deterrent. Broadly speaking I think that those who were operated on benefited by it.

The commonest valvular lesion, as might be expected, was mitral regurgitation : 49 cases, as compared with 18 in which there was stenosis, and 9 in which there were mitral and aortic lesions. Only two of these children had no evidence of valvular lesion on first reporting to hospital : in all the others the valvular lesion was already obvious and some damage already done. One of these two children (No. A.8) was admitted in 1924 for 4 weeks, 3 days after the onset of joint pains ; her heart was apparently normal when she left Hospital. On being sent for in December, 1926, for re-examination, she had had no recurrence, she had no symptoms, her electrocardiogram was normal, but a short apical systolic murmur strongly suggested that carditis had occurred. The other child was at first considered to be a purely myocardial case, but, when she last reported at hospital after a long interval, she was found to have developed a mitral lesion.

Of the 9 cases where a diagnosis of pericarditis was made, only one showed involvement of the pericardium without evidence of endocarditis. This was a very acute case which cleared up rapidly and has not, to my knowledge, recurred. 
The 3 cases on whom I have made a provisional diagnosis of myocarditis only are as follows :-

CASE 1. A.9: male at. 14 years. Tachycardia noted at each examination from 1924 till 1927 ; rate varies from 132-144; hæmic murmur over base ; electrocardiogram shows inversion of $\mathrm{T}$ wave in lead 3 .

CASE 2. A.13 : female, cet. 10 years. In Oct., 1926, admitted as a cardiac suspect; history of tonsillitis, slight pains; had tonsillectomy performed, December, 1926. Pulse rate persistently rapid. Ecg. in December, 1926, and January, 1927, showed only inversion of $\mathrm{T}$ wave in lead 3, but on 4th November, 1927. $T$ wave in lead 2 was noted to be flattened. This is the only case in this series in which I have observed flattening of $\mathrm{T}$ in lead 2. (Fizs. 1 and 2.)

CASE 3. A.38 : Dr. Simm's patient, male, at. 6. This boy has no obvious valvular lesion, but has frequent and persistent ventricular extra-systoles, marked inversion of $\mathrm{T}$ III, and his cardiogram is of left ventricular predominance type. He has also clinical and X-ray evidence of tracheo-bronchial adenitis. His tonsils were large and have been removed. His mother says he is " in the best of health " after a long course of sodium salicylate, but his arrhythmia and his electrocardiogram are unchanged. (Fig. 3.)

These cases, where there is no obvious endocarditis, are at once difficult and interesting, and I hope to watch their development.

Of the 72 cases examined by the electrocardiograph, 33 showed normal records. The majority of these were cases of early and uncomplicated mitral regurgitation. Four cases of mitral stenosis showed normal cardiograms, and so did 3 cases of aortic regurgitation with mitral regurgitation and stenosis. I suppose that in these last cases the balance between the two ventricles, both of which are enlarged, has been maintained in normal ratio. I think that these are the relatively favourable cases of mixed aortic and mitral lesion.

I have kept separate from these the 9 cases in which the record was normal except for inversion of $\mathrm{T}$ in lead 3 . While it is universally recognized that inversion of $\mathrm{T}$ in leads 1 and 2 is " a sign of ill-omen " and indicative of serious myocardial change, there is still uncertainty as to the reason why the $\mathrm{T}$ wave in lead 3 may be inverted in records of hearts that are otherwise normal.

The question of right and left ventricular predominance is not any simpler. In this group, 4 children showed right ventricular predominance to a greater or less extent; two had mitral stenosis, two mitral regurgitation ; one of each

TABLE II.

Electrocardiographic Results.

\begin{tabular}{|c|c|c|c|c|c|c|c|c|c|c|}
\hline \multicolumn{6}{|c|}{ Electrocardiograms. } & A & B & $\mathrm{C}$ & $\mathrm{D}$ & $\mathbf{E}$ \\
\hline Cases examined & $\ldots$ & . & . & . & . & 72 & 10 & 18 & 15 & 8 \\
\hline Normal & $\ldots$ & . & . & . & . & 33 & 4 & 9 & 13 & 6 \\
\hline Inverted $\mathrm{T}$ in lead 3 & . & . & . & . & $\ldots$ & 9 & 1 & 3 & 2 & 2 \\
\hline R. V. predominance .. & $\ldots$ & . & . & . & . & 4 & 1 & 1 & - & 一 \\
\hline L. V. predominance .. & $\ldots$ & . & . & . & $\ldots$ & 11 & 1 & 5 & - & 一 \\
\hline Large or notched $\mathbf{P}$ wave & . & . & . & . & . & 10 & 2 & 2 & - & 一 \\
\hline Extra-systoles only .. & . & . & . & . & . & 2 & 1 & 1 & - & - \\
\hline Aur. fibrillation or flutter & $: \cdot$ & . & . & . & . & 2 & - & - & - & - \\
\hline Long P-R interval $\ldots$ & . & . & . & . & . & 1 & - & - & - & 一 \\
\hline
\end{tabular}


kind is dead. Both of the survivors have been X-rayed and in each case the report is " heart enlarged both to right and left." As compared with these four cases, 11 cases showed evidence of left ventricular predominance. I was at first surprised at this in view of the frequent involvement of the mitral valves as compared with the aortic. It is, however, in accordance with what Pardee ${ }^{1}$ of New York has found. He says: "Mitral stenosis leads to an hypertrophy of the right ventricle through a damming back of blood in the pulmonary capillaries, thus increasing its work. Mitral regurgitation does this also though secondarily and only after overtaxing the left ventricle. Hence the earliest records with this valve lesion may show a left ventricular predominance, later ones giving a normal Q.R.S., and later still, as stenosis develops, a right predominance." Of the 11 cases of this left ventricular type four had aortic regurgitation, five had mitral regurgitation, one had pericarditis without obvious endocarditis and one was the case of Dr. Simm's, No. A.38, whom I have already described as a case of myocarditis. The X-ray findings were as follows: 8 were $\mathrm{X}$-rayed and in 7 of these the heart was described as being enlarged, principally to the left side, and in 1 the description was "heart generally enlarged."

Two additional factors must, of course, be borne in mind. First, ordinary radiography of the chest gives some degree of distortion of the size and shape of the heart. This can only be obviated at considerable expense by the installation of an orthodiagraph or of so powerful a plant as to enable the radiographer to expose his patient to the rays at a distance of more than seven feet from their source. There is this defence to the ordinary method, that the children are all radiographed with the same technique and the degree of distortion is more or less the same for all.

The other factor is that the heights of the $\mathrm{R}$ and $\mathrm{S}$ waves, by which predominance of one or other ventricle may be indicated, are also affected by the anatomical position of the heart in the chest and in particular by the position of its electrical axis. Pardee ${ }^{1}$ sums up his consideration of the facts by stating that " in general, this electrocardiographic sign . . . is found to be correct and especially if there are evidences of cardiac enlargement . . . the clinical pathological studies so far reported correlating the electrocardiographic predominance with the relation of the ventricular weights show that in $\mathbf{7 5} \%$ of instances, the electrocardiogram will suffice to place the ventricular relations."

As might be expected, enlargement or notching of $\mathrm{P}$, indicative of auricular overaction was a relatively common finding, occurring in 10 cases, all of which had mitral involvement. Only two records show extra-systoles, though these were sometimes detected clinically in other cases.

There were two cases of delirium cordis : one a girl, (A.63) of 13 years (Fig. 5) who has auricular fibrillation varied by periods of flutter, and the other a girl of 5 (A.67) who was admitted with a tachycardia of 200 per minute, due $I$ think to 1 in 1 flutter; this child died soon afterwards. On commencing this enquiry I expected to find many more cases of rheumatic heart block, but in only one case in this group did I find a prolonged P-R 

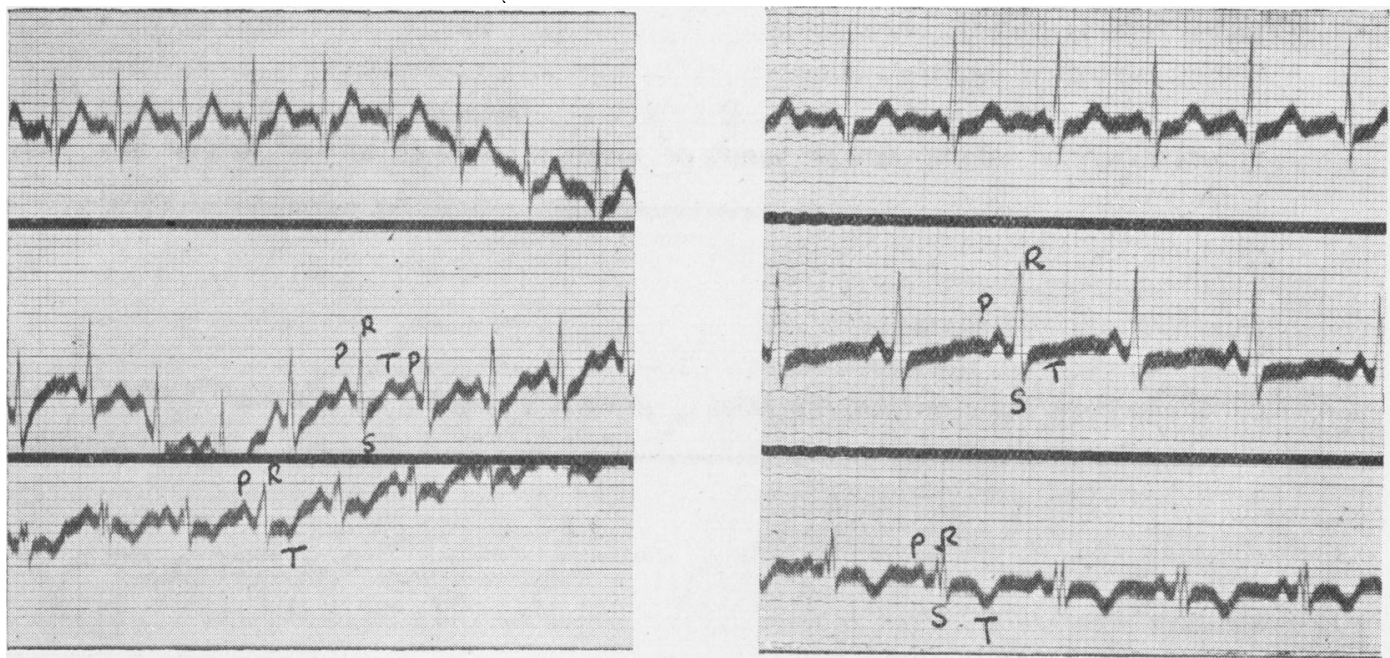

Figs. 1 and 2. CASE No. A. 13. R.T. Female ret. 9.

First electrocardiogram $(3 / 12 / 26)$ showed inversion of $\mathrm{T}$ in lead 3 only. Last electrocardiogram (4/11/27) showed inversion in 3, and flattening in lead 2. Heart persistently rapid (ca. 144). X-ray : Heart normal
in size.

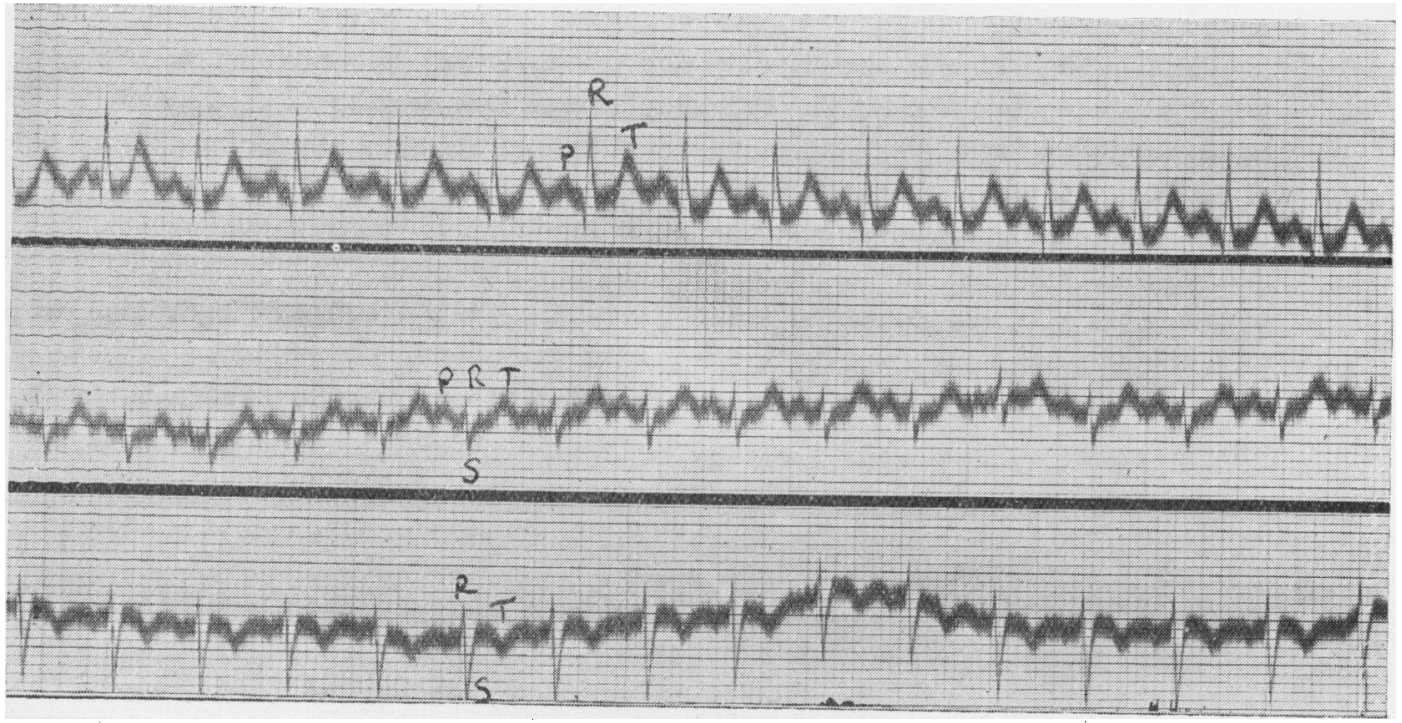

Fig 3. Case No. C. 22 . Male at. 11.

Chorea, treated in U.H.C.W. Heart apparently normal. Electrocarliogram : Of type associated with left ventricular predominance. Inversion of $\mathrm{T}$ in lead 3 , X-ray: Heart enlarged generally
and to left. 


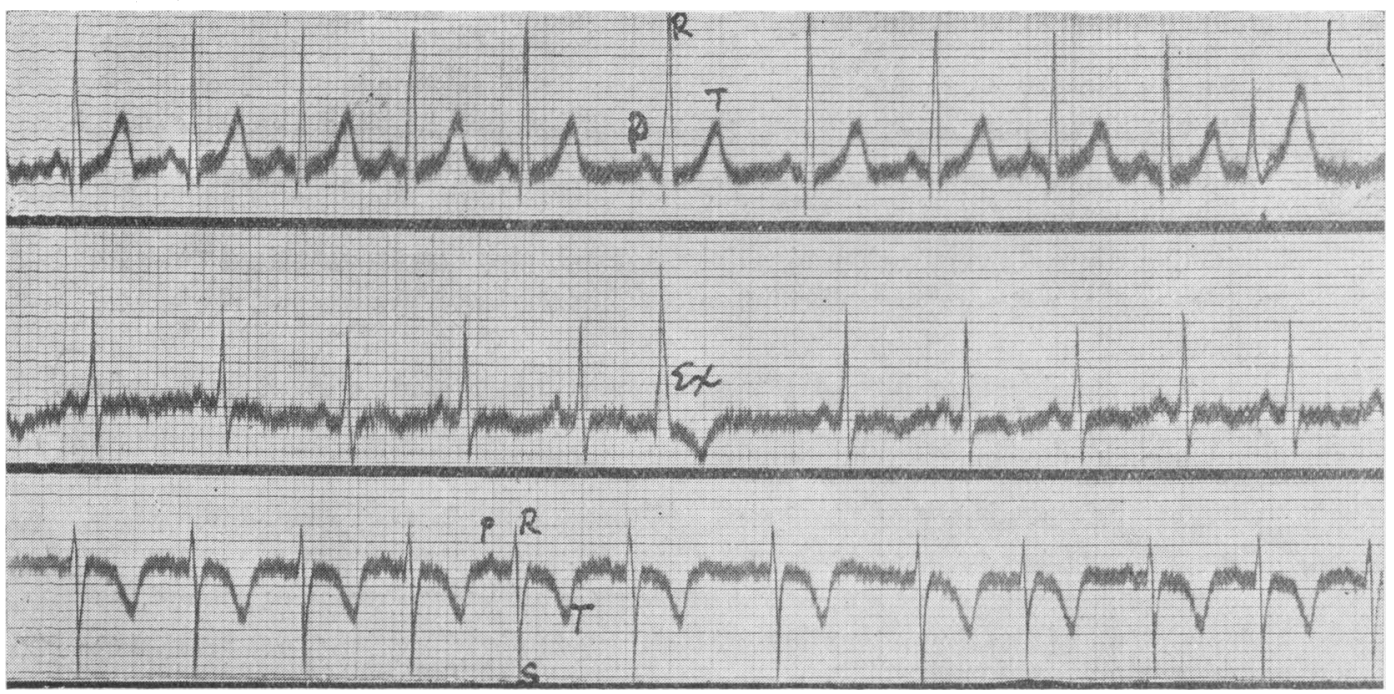

Fig. 4. Case No. A 38. T.K. Male iet. 6.

Electrocardiogram : One extra-systole is seen in lead 2. The high $\mathrm{R}$ in le:t 1 , together with the deep $\mathrm{S}$ in lead 3, suggest left ventricular predominance. X-ray: Root shadows increased; peribronchial fibrosis; ?? early T, B.

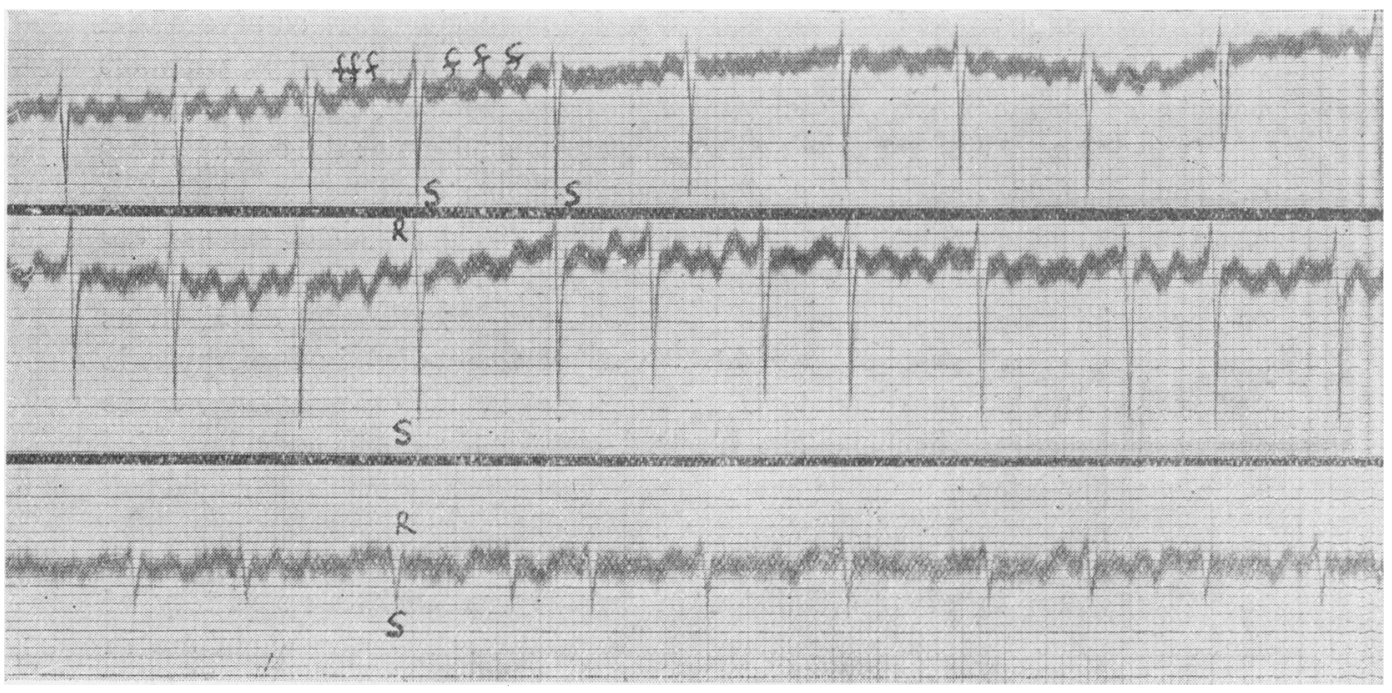

Fig. 5. CaSe No. A 63. B.W. Female ret. 13.

History of "Growing Pains." Mitral Regurgitacion. Electrocardiograin shows auricular fibrillation with priods of flutter. X-ray : Heart enlarged to right and generally. 
interval. This boy (A.34) had a P-R interval of 0.2 sec. which is about the normal maximum interval ; he had a hypertrophied heart and mitral stenosis with a tendency to tachycardia.

I should like to emphasize the importance of the observation that of these 79 children, only one is noted to have sinus arrhythmia. This bears out Sir James Mackenzie's ${ }^{2}$ dictum that it "is a sign of a healthy heart muscle," but like almost every other sign in medicine, there are exceptions and its presence does not constitute absolute proof that the heart has escaped rheumatic attack.

The classification into slight and severe heart disease is at best only conjectural, but is in itself evidence of the serious problem which confronts us. If I am right, of these 79 children 57 have a serious, crippling, and ultimately fatal disease of the heart. Of these 9 are already dead.

Group B. (Limb-pains, Chorea and Carditis).

This is a smaller group, but it presents a still more serious problem, as rheumatism of the limbs together with chorea appear to represent a still more serious infection. It will be seen that girls were still more frequently the victims, that a larger proportion were in-patients, and for longer periods. Every one of these children had evidence of carditis when first seen at hospital, and in seven at least the heart lesion is now more serious than when first observed. Three are known to have had slight recurrences of chorea, and three have had slight pains in the limbs since first coming under treatment. It is regretted that only three of the nine who had tonsillitis have had their tonsils removed. I think the main reason for this is that one hesitates to recommend tonsillectomy while the choreic movements persist, and when they are better the parents do not wish the child to be re-admitted for operation. Mitral lesions predominate, as the table shows, and I have diagnosed as myocardial a case where a boy (B.16) has a large heart on X-ray examination, with left ventricular predominance by electrocardiograph, but no obvious murmur.

There was nothing remarkable in the electrocardiograms : the case showing evidence of right ventricular predominance was one of mitral regurgitation and the X-ray report was " heart enlarged to right." No single case of the series had persistent sinus arrhythmia; one girl had it in the earlier days of her carditis but it disappeared. Fourteen are provisionally classified as severe cases of whom two have died. One of these died in hyperpyrexia during her first attack of acute chorea. The other had rheumatism, acute chorea and pericarditis; she left hospital apparently doing well but died some months later.

Group C. (Chorea, Carditis, no limb-pains).

This group is of the children in whom was elicited no history of limb-pains, but who had chorea and heart trouble. Females again are in the majority, and 16 of the 24 were treated as in-patients. All 24 would have been in-patients, if they had been seen during their firstattack and their parents had been willing. Two of the children gave a history of an attack precipitated by emotional stimulus, grief or fright. There were 5 cases of mitral stenosis, 
seventeen of mitral regurgitation, and two, diagnosed as in Groups A \& B as myocarditis on the grounds of a left ventricular predominance (Fig. 3) together with an X-ray finding of hypertrophy. I wish to make it clear that I am not dogmatic about this type of child, but only that I cannot classify it as having no evidence of carditis.

TABLE III.

Frequency of Choreic Attacks.

Number of Attacks of Chorea.

\begin{tabular}{|c|c|c|c|c|}
\hline & & Group & Group & Group \\
\hline & & B & $\mathrm{C}$ & $\mathrm{E}$ \\
\hline$\ldots$ & . & 13 & 13 & 22 \\
\hline$\ldots$ & . . & 2 & 5 & 4 \\
\hline .. & .. & 0 & 4 & 0 \\
\hline . & . & 1 & 1 & 1 \\
\hline . & .. & 0 & 1 & 0 \\
\hline
\end{tabular}

Three others showed records of this left ventricular type but have endocarditis: two have mitral regurgitation and one has mitral stenosis. One girl (No. C.8) had mitral stenosis with right ventricular preponderance. She has since died.

The case showing sinus arrhythmia is interesting :

No. C. 20, a girl, aet. 11, came to hospital in March, 1925, during her third attack of chorea. She had a rough apical murmur strongly suggesting early stenosis. She has been seen at frequent intervals since; her cardiac condition is no worse, and she still has sinus arrhythmia.

Nineteen of the twenty-four have been classified as having severe heart lesions, and of these two are already dead.

\section{Groups $D$ (limb pains alone) and $E$ (chorea alone).}

I do not propose to give detailed descriptions of these cases. In some cases a systolic apical murmur was recorded, and this disappeared. I cannot express an opinion whether this was caused by a carditis so slight as to leave no obvious valvular lesion in its train. It seems to be the case that the appearance of an apical systolic murmur in a rheumatic child does not necessarily mean that he is doomed to cardiac disablement. Twenty-six cases of group $\mathrm{D}$, and twenty of group $\mathrm{E}$ have been re-examined within the past three months.

I find it difficult to assess the severity of the rheumatic pains or the chorea in these non-cardiac cases as compared with groups A, B \& C. Some of the choreic cases were certainly very severe; seven of them should perhaps have been grouped apart, as they had limb pains as well as chorea, but usually slightly. It is noteworthy that many severe cases of chorea, with frequent recurrences, never develop carditis, and one sometimes wonders if this is due to a different causative agent. 


\section{SUMMARY.}

On a general re-survey of the 5 groups, one notes the absence of any case of a purely aortic lesion without mitral involvement; the comparative frequency of evidence of predominance of one or other ventricle, sometimes without obvious endocarditis ; the fact that right ventricular predominance in childhood is apparently of serious prognostic significance (three of the six cases in which it appeared are already dead) ; that fourteen out of 61 " noncarditic" children showed sinus arrhythmia, but only 2 out of 119 cases of heart discase ; and, most significant of all, that in all but two of the cases of valvuiar disease of the heart, the presence of a murmur was noted on the hild's first visit to hospital.

\section{Treatment.}

All, or almost all, of these children have been treated by the administration of sodium salicylate with twice its weight of sodium bicarbonate, and, where the parents co-operated, this was continued for many months, varied from time to time with iron, usually in the form of the syrup of the iodide. "Rheumatism is a smouldering fire" as Poynton said, and I am inclined to the belief that it is during the smouldering stage as much as during the acute conflagration that sodium salicylate is indicated. I admit that Poynton ${ }^{3}$ states that "his experience of salicylates is so unsatisfactory that ... in the most formidable cases of carditis in the young his best results have been obtained without their use."

Carey Coombs ${ }^{4}$ on the other hand states that " often it is an advantage to prolong its administration after discharge from hospital ". His own experience leads him to the belief that the administration of salicylate does limit the cxtent of the cardiac lesions, probably by attacking the micro-organisms somewhere between their portal of entry into the circulation and their final settiement in the cardiac tissues. No other drug has a similar action; to that extent therefore salicylate is a specific for rheumatic infection. Lutenkacher' of Paris gives large doses for 15-20 days after the temperature of acute rheumatism has fallen and continues the administration of the drug for 12-18 months after the apparent cessation of all symptoms. Kerley ${ }^{6}$ of New York gives 10 grains daily for 5 days in each 15 , for 6 months, and for 5 days in each 30 for a further 6 months. Parkinson ${ }^{7}$ advises its administration for many weeks after an attack, especially during the winter months, with iron and cod liver oil as accessories. Miller ${ }^{8}$ who has enquired very closely into this matter says that he believes that the more freely and persistently we use salicylate in the earlier rheumatic attacks the less often we shall be faced with dreadful failures.

I think it must be an argument in favour of this method of treatment that only two of these Ulster Hospital children have developed a definite endocarditis who were free from murmurs when they first came under treatment and it may be a reason why nine had only transient murmurs. 
While emphasizing its importance I do not wish to minimize the value of other aspects of treatment : rest in bed during any rheumatic manifestation and for some time afterwards is of primary importance. As a rule I think these children, particularly the chorea cases, can be nursed better in hospital than in their own homes. Of these 180 children, 89 were in-patients, representing 645 weeks in the Ulster Hospital alone, at a cost of about $£$ (970.

My attitude to tonsillectomy may be summed up in the statement (I do not know its author) that "tonsils are as frontier forts which, when they have fallen into the hands of the enemy, are no longer a defence but a menace to our safety."

Dr. T. H. Davey in Sir Thomas Houston's Laboratory kindly examined a few of the tonsils after removal in the hope of finding the newly described bacillus cardio-arthritidis but without success.

This uncertainty as to the causative factor is the cause of difficulty not only in diagnosis and treatment, but in ascertaining when quiescence or cure has been reached, and this necessitates prolonged medical supervision.

In America the American Heart Association has done a great deal to educate public opinion about the importance of early symptoms. Near the larger cities in England and in America special country homes have been devoted to the after treatment of these children ; gradual physical exercises, education and vocational training are given according to the physician's recommendation. This last point is of the utmost importance. These children must be trained for sedentary occupations rather than be allowed to drift casually into heavy work for which they are not fitted.

In Bristol, Dr. Askins, the School Medical Officer has issued a circular letter to all School-teachers, warning them of the importance of growing pains, shortness of breath and nervous twitchings as evidence of rheumatism and potential heart disease. I think it is an excellent thing to encourage the co-operation of the school-teachers in this way.

In the Ulster Hospital, the Medical Staff is about to ask the Board of Management to print a leaflet of instructions to parents on the care of Rheumatic children. This leaflet is based on a similar one issued at Paddington Green Children's Hospital.

A series of cases such as this is an argument in favour of compulsory notification of rheumatism in children. This experiment is at work in parts of London and is an example which might well be copied in Northern Ireland, where comparison could then be made of its incidence in town and country. Country doctors seem to regard these cases as very rare in their practices, and this is apparently the experience of School Medical Officers in rural districts. The information gained by even an experimental year or two of compulsory notification would be invaluable, and would bring home to the profession and the public the prevalence of the disease. This has been well expressed by Poynton in his preface to Carey Coombs' book " Rheumatic Heart Disease." "Surely the time has come to turn to rheumatism and particularly acute rheumatism in the young. Such patients must have the sympathy of all, for none appeals more than the child with rheumatic heart disease who is the most 
alert and engaging of all our patients. If ever a medical venture on a large scale was indicated in this country, it is the prevention of rheumatic heart disease, and by this the writer means the supervision and care of the rheumatic child, adolescent and adult."

I should like to express my thanks to my colleagues and to Miss Martin and Sister McCaughey of the Hospital for their invaluable help in various aspects of the work.

\section{REFERENCES.}

1. Pardee, Clinical Aspects of the Electrocardiogram, 47, 48.

2. Mackenzie, J., Diseases of the Heart, 3rd. Ed. 187.

3. Poynton, F. J., Brit. Med. J., Lond., 1924, 986.

4. Coombs, C. F., Rheumatic Heart Disease, Bristol, 1924, 323.

5. Lutembacher, Med. Sci. Abst. \& Rev., Lond., VI, 97.

6. Kerley, C. G., Practice of Pediatrics, Philad., 2nd Ed., 723.

7. Parkinson, J., Personal Communication.

8. Miller, R., Brit. Med. J., Lond., 1923, ii, 704. 